\title{
Nicolau Syndrome in Patient Following Diclofenac Administration: A Case Report
}

\author{
Kwang-Kyoun Kim, M.D., Ph.D. \\ Department of Orthopedic Surgery, Konyang University College of Medicine, Daejeon, Korea
}

\begin{abstract}
Nicolau syndrome is a rare adverse reaction to a variety of intra-muscular drug preparations. The typical presentation is pain around the injection site soon after injection, followed by erythema, livedoid patch, hemorrhagic patch, and finally, necrosis of skin, subcutaneous fat, and muscle tissue. The phenomenon has been related to the administration of a variety of drugs, including non-steroidal anti-inflammatory drugs, corticosteroids, and penicillin. We report a case with typical features associated with diclofenac injection for pain control in a patient who had undergone bilateral total knee arthroplasty. (Ann Dermatol 23(4) 501 503, 2011)
\end{abstract}

\section{-Keywords-}

Diclofenac, Nicolau syndrome, Total knee arthroplasty

\section{INTRODUCTION}

Nicolau syndrome is a rare adverse drug reaction that occurs at the site an intramuscular injection. It was first described in the 1920s in a patient treated with bismuth salts for syphilis ${ }^{1,2}$. The phenomenon has been related to the intramuscular administration of a variety of drugs, including non-steroidal anti-inflammatory drugs (NSAIDs), corticosteroids, and penicillin. Histologic findings include thrombosis of vessels in the reticular dermis. Patients who

Received June 7, 2010, Revised December 3, 2010, Accepted for publication December 3, 2010

Corresponding author: Kwang-Kyoun Kim, M.D., Ph.D., Department of Orthopedic Surgery, College of Medicine, Konyang University, 685 Gasuwon-dong, Seo-gu, Daejeon 302-718, Korea. Tel: 82-42-600-6902, Fax: 82-42-545-2373, E-mail: ajouos@hanmail.net

This is an Open Access article distributed under the terms of the Creative Commons Attribution Non-Commercial License (http:// creativecommons.org/licenses/by-nc/3.0) which permits unrestricted non-commercial use, distribution, and reproduction in any medium, provided the original work is properly cited. undergo total knee arthroplasty experience severe pain postoperatively, so surgeons frequently prescribe NSAIDs, which are administered intramuscularly, for pain control. We report a patient with typical features of Nicolau syndrome following diclofenac injection who underwent bilateral total knee arthroplasty.

\section{CASE REPORT}

A 69-year-old moderately obese woman $(77 \mathrm{~kg}, 157 \mathrm{~cm})$ underwent bilateral simultaneous total knee arthroplasty. Her body mass index was $31.2 \mathrm{~kg} / \mathrm{m}^{2}$, and she had a medical history of diabetes and hypertension. She was being discharged the following day, and her progress was good. The night before discharge, immediately after the diclofenac injection, the patient complained of intense pain in her right buttock. The skin was swollen and showed diffuse redness, with blanching at the injection site. The next morning, the area around the injection site was exquisitely tender to palpation. The skin showed erythematous maculae and a livedoid violaceous patch with dendritic extensions. The initial differential diagnosis included allergic reaction to the diclofenac, acute bleeding, hematoma, and acute compartment syndrome. On the second day post-injection, her skin turned dark purple with a hemorrhagic patch. By the $10^{\text {th }}$ day post-injection, the erythematic area had decreased, but most of the darkly colored skin had progressively turned black. Two weeks later, the black skin had changed into an eschar (Fig. 1). Three weeks later, when the progression had stopped, we persuaded her to undergo surgical debridement of the necrotic tissue. We preoperatively checked the computed tomography (CT) scan to define the extent of the lesion, muscular involvement, hematoma, and fluid collection. CT scan revealed only diffuse infiltration into the subcutaneous adipose tissue at the injection site. The muscles had been spared, and no liquid had collected under the 


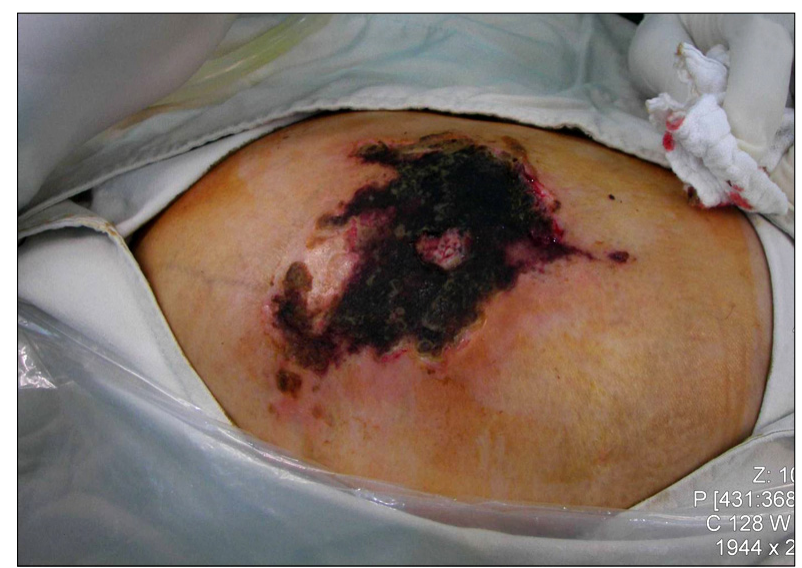

Fig. 1. Photography of right gluteal lesion three weeks post injection illustrating the nature and extent of the eschar.

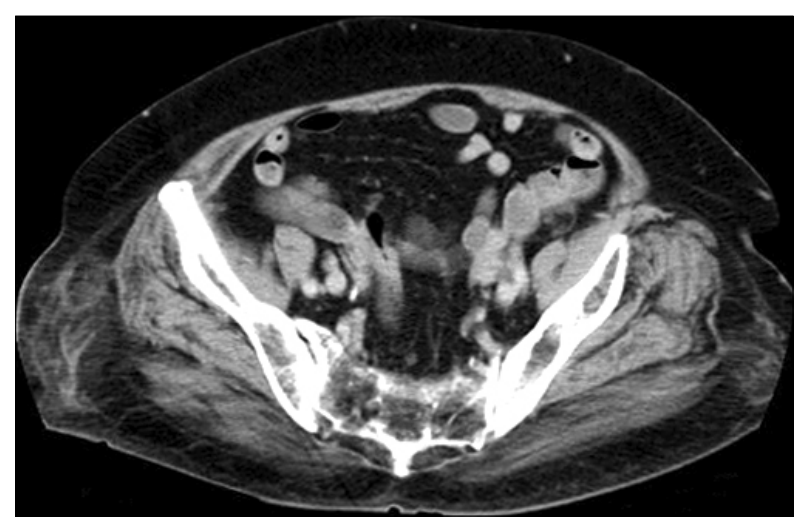

Fig. 2. Post gadolinium enhanced computed tomography (CT) scan. The CT scan image showed an enhanced subcutaneous infiltration in the right buttock. There was no evidence of underlying muscle involvement, hematoma, or acute bleeding.

eschar (Fig. 2).

The first debridement was performed across an area $20 \times$ $14 \mathrm{~cm}$ and confirmed that the necrosis extended to the patient's skin and subcutaneous fat, but the underlying muscles were intact. We covered the defect with a full-thickness skin graft. Two months later, the lesion had healed, leaving only a residual scar (Fig. 3).

\section{DISCUSSION}

No tool or test exists for making a confirmative diagnosis of Nicolau syndrome; it is based purely on the clinical features and their correlation with previous case reports. One report suggests that laboratory tests reveal creatine kinase and myoglobin as well as other markers of muscle damage $^{3}$, but that author thought that a mere increase in creatine kinase and myoglobin does not automatically mean necrosis with muscle involvement. In addition, our

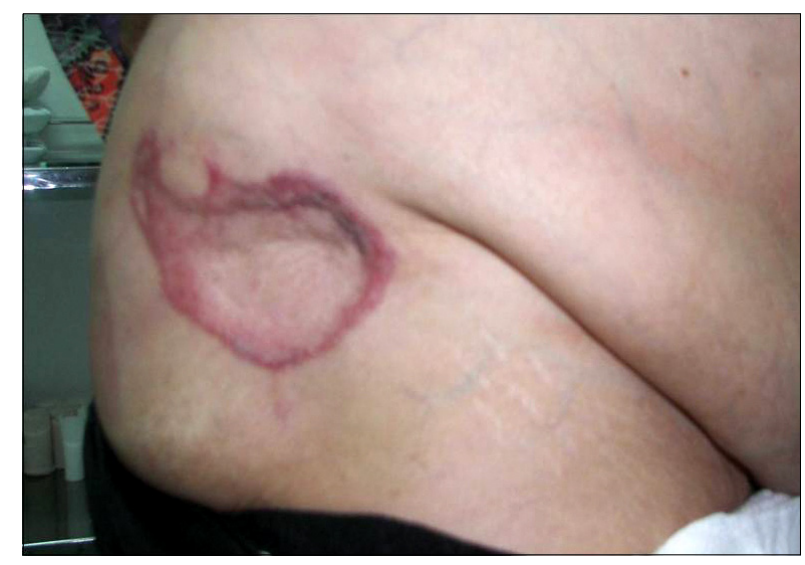

Fig. 3. Two months later, the defect appeared completely healed, with a small depressed scar.

patient experienced no increase in creatine kinase or myoglobin.

Necrotic ulcers usually heal in several months, leaving an atrophic scar. However, transient or permanent ischemia of the ipsilateral limb and various neurological complications sometimes develop ${ }^{4}$. Our patient's lesion rapidly progressed to extensive necrosis and, despite conservative therapy, needed surgical reconstruction. Diclofenac is a cyclooxygenase inhibitor and thus shares the pharmacodynamic properties of NSAIDs, with inhibition of prostaglandin synthesis resulting in the vasoconstrictive phenomenon. In this case, injection of diclofenac was followed by the application of a cool pack that could mediate additional local vasospasm in the context of arterial narrowing. We suggest that both mechanisms contributed in a detrimentally synergistic fashion to the magnitude of her acute vasospasm. That might be the reason for the rapid progression to necrosis of our patient's lesion.

Experimental studies have disproven the original hypothesis of Nicolau syndrome's allergic and immunologic origins. Most significantly, a patient's reinjection with the agent that caused Nicolau syndrome has not induced recurrence ${ }^{1}$. Our patient had received intramuscular diclofenac before and after the development of Nicolau syndrome, but the adverse reaction did not recur. Several theories exist. First, an intra-arterial, periarterial, or perinervous injection might produce intense local pain and a secondary vasospasm owing to sympathetic nerve stimulation, leading to ischemia with subsequent muscular and/or cutaneous necrosis. Second, an inadvertent intra-arterial injection of solutions intended for intramuscular use might cause embolic occlusion of small skin arteries. Third, vascular or perivascular injection might produce marked inflammation and progressive necrosis of 
the intima, destroying the whole arterial wall and causing necrosis of the skin.

Subcutaneous instead of intramuscular injection was an important contributing factor in several reports ${ }^{5-7}$. Cockshott et al. ${ }^{6}$ highlighted the difficulties of administering intramuscular injections. Only $5 \%$ of females and $15 \%$ of males can receive a gluteal injection with a standard $3.5 \mathrm{~cm}$ needle. Okan and Canter $^{7}$ described subcutaneous injection and injury to cutaneous arteries, leading to subcutaneous fat and skin necrosis. In our case, the injection could have been subcutaneous due to her obesity and difficulty in position change. CT scan demonstrated only diffuse infiltration in the adipose tissue at the injection site. A sufficiently long needle for an obese patient, the Z-track method of intramuscular injection, injection only after aspiration with a syringe, and an injection in the upper outer quadrant of the gluteal region, which has few large blood vessels, can minimize subcutaneous irritation.

In our case, it was difficult to differentiate Nicolau syndrome from acute compartment syndrome, which presents with severe pain, pallor, and swelling. In acute compartment syndrome, treatment is early surgical decompression within 12 hours to prevent irreversible changes of nerve and muscle. CT is a useful tool for differentiation. In acute compartment syndrome, there is hematoma or fluid collection on the buttock.

Although physicians have recognized rapid vasoactive therapy with subcutaneous heparin as beneficial, no specific therapy for Nicolau syndrome exists other than prevention. Clinicians should be aware of this complication and avoid unnecessary intramuscular drug injections. Finally, physicians should consider Nicolau syndrome as a diagnostic possibility for anyone presenting with severe localized pain following an intramuscular injection of any substance.

\section{REFERENCES}

1. Faucher L, Marcoux D. What syndrome is this? Nicolau syndrome. Pediatr Dermatol 1995;12:187-190.

2. Köhler LD, Schwedler S, Worret WI. Embolia cutis medicamentosa. Int J Dermatol 1997;36:197.

3. Hamilton B, Fowler P, Galloway H, Popovic N. Nicolau syndrome in an athlete following intra-muscular diclofenac injection. Acta Orthop Belg 2008;74:860-864.

4. Ruffieux PH, Salomón D, Saurat JH. Livedo-like dermatitis (Nicolau's syndrome): a review of three cases. Dermatology 1996;193:368-371.

5. Lie C, Leung F, Chow SP. Nicolau syndrome following intramuscular diclofenac administration: a case report. J Orthop Surg (Hong Kong) 2006;14:104-107.

6. Cockshott WP, Thompson GT, Howlett LJ, Seeley ET. Intramuscular or intralipomatous injections? N Engl J Med 1982;307:356-358.

7. Okan G, Canter HI. Nicolau syndrome and perforator vessels: a new viewpoint for an old problem. Cutan Ocul Toxicol 2010;29:70-72. 